\title{
Design de produto aplicado à cultura slow: mobiliário urbano modular
}

Product design applied to slow culture: modular urban furniture

VICTORIA, Isabel Cristina Moreira; Mestranda; Universidade Federal de Santa Catarina

Isabel.mvictoria@gmail.com

FIGUEIREDO, Luiz Fernando Gonçalves de; Doutor; Universidade Federal de Santa Catarina

Iff@cce.ufsc.br

\section{Resumo}

A sociedade atual vive em um contexto tumultuoso, sendo comum as pessoas viverem estressadas, se alimentando mal e convivendo cada vez menos com as pessoas, perdendo oportunidades de fazer e manter relacionamentos pessoais. Como este estilo de vida está saturado, existem diversos estudos que comprovam a tendência de que as pessoas buscarão um melhor aproveitamento do seu tempo, prestando atenção no que consomem, dando valor ao seu próprio bem-estar e valorizando o prazer de estar em um meio social. Nesse contexto, o objetivo deste trabalho é contribuir por meio do design de produto, para o incentivo e a prática da cultura Slow e, dessa forma, promover a preocupação com o bem-estar pessoal e comunitário. 0 método de pesquisa usado é descritivo e neste projeto foi utilizado como metodologia o Guia Projetual NASDesign. Ao final, conclui-se que o mobiliário urbano proposto atende uma lista de requisitos baseadas no bem-estar dos usuários.

Palavras Chave: design de produto; cultura slow; mobiliário urbano.

\begin{abstract}
Current society lives in a tumultuous context, with people often living under stress, eating poorly and living less and less with people, losing opportunities to make and maintain personal relationships. As this lifestyle is saturated, there are several studies that prove the tendency that people will seek a better use of their time, paying attention to what they consume, giving value to their own well-being and valuing the pleasure of being in a medium Social. In this context, the objective of this work is to contribute through the product design, to the incentive and the practice of Slow culture and, in this way, to promote the concern with personal and community well-being. The research method used is descriptive and in this project was used as methodology the NASDesign Project Guide. At the end, it is concluded that the proposed urban furniture meets a list of requirements based on the well-being of the users.
\end{abstract}

Keywords: product design; slow culture; urban furniture. 


\section{Introdução}

A sociedade atual vive em um ritmo extremamente acelerado. As pessoas dormem pouco, vivem preocupadas com suas obrigações profissionais, se alimentam com pressa, estão sempre atentas aos mais variados meios tecnológicos (tablets, celulares, computadores...) e diminuíram consideravelmente o contato físico com as outras pessoas, procurando envolver-se apenas com seus próprios problemas e dispensando ajuda de outros indivíduos. Todas essas características são nocivas à saúde mental e física das pessoas, prejudicando o próprio corpo e os relacionamentos pessoais da população.

Alguns movimentos incentivam as pessoas a desacelerar o ritmo, propondo uma reavaliação de prioridades e do uso do tempo. Um desses movimentos é o Slow Food, que surgiu para contrapor o já disseminado Fast food, se opondo a padronização do alimento. O movimento propõe uma melhor qualidade na alimentação das pessoas incentivando o consumo de alimentos que não levem tantos produtos químicos em seus componentes, além de incentivar o contato com o preparo dos alimentos e a calma para realizar a refeição, observando texturas, cheiros e sabores.

Característica também comum na sociedade atual é a individualidade e a falta de habilidade em utilizar o tempo a seu favor, utilizando-o apenas para obrigações. Alguns povos espalhados pelo mundo possuem enraizados em suas culturas um equilíbrio no uso do tempo, para o povo de Kelantese, na Malásia "a pressa é considerada uma falta de ética por reduzir o tempo disponível para visitar e socializar com amigos, parentes e vizinhos" (THACKARA, 2008). A partir do já mencionado Slow Food e de comunidades como a de Kelantese, outros movimentos foram criados, como a cultura slow, que preza pelo bem-estar das pessoas e por um equilíbrio no uso do tempo. Organizações de pequenos grupos que buscam levar uma vida mais leve, tentando encontrar o equilíbrio entre o estresse ao qual as pessoas já estão habituadas e a tranquilidade a qual as pessoas buscam.

Estudos de tendências revelam que nos próximos anos as pessoas tendem a ter uma preocupação maior com seu bem-estar físico e psicológico, também haverá uma maior responsabilidade social e ambiental, em que o indivíduo se inclina às necessidades de sua comunidade e pensa nas gerações futuras, buscando formas de consumo menos impactantes ao meio-ambiente (FUNDAÇÃO TELEFÔNICA, 2015) (EUROMONITOR, 2016) (BAIN E COMPANY, 2016).

Pensando nesse contexto, este projeto busca contribuir por meio do design para a motivação à cultura slow, trazendo os princípios desse movimento para o produto, propondo o bem-estar das pessoas como prioridade e proporcionando interação social, cooperação entre indivíduos, contato com a natureza, interesse por hábitos saudáveis de consumo, oportunizando uma inovação social na comunidade em que o objeto estiver inserido. Para abordar este tema será utilizada a vertente do design que se dedica a criação de produtos e o produto em questão será um mobiliário urbano.

\section{Metodologia}

Para execução do projeto foi utilizado o Guia Projetual NASDesign. O método consiste em uma "abordagem sistêmica, onde o design é entendido como um processo holístico, e, dessa 
forma, o foco é deslocado do produto final para o sistema produtivo e suas complexas interações" (AROS, 2016, p. 46).

Esse método consiste em três fases: "Sentir", "Agir" e "Realizar". A fase "Sentir" é o primeiro contato com a comunidade, em que define-se a problematização e ocorrem as primeiras conversas e experiências com a comunidade estudada, coletando informações e conteúdo para o projeto. A segunda fase é "Agir", nela busca-se desenvolver soluções tangíveis, com o apoio e participação do público-alvo. A terceira fase é "Realizar", e fundamenta-se em implementar o produto final e dar suporte à comunidade se necessário.

\section{Cultura Slow}

Slow é uma palavra inglesa, que tem por significado "devagar", "lento", "retardar" ou "desacelerar".

A cultura slow faz parte de um movimento que preconiza o bem-estar e desenvolvimento pessoal, social, comunitário e ambiental. O Movimento Slow é um movimento internacional criado a partir do Slow Food e tem se espalhado pelo mundo, com cada vez mais adeptos. Esses adeptos não se encaixam em um perfil único, mas identificam-se com a ideia geral do movimento, que possui princípios como valorizar a qualidade e não quantidade (em relações pessoais, profissionais ou hábitos de consumo), dar mais valor ao essencial, apreciar cada momento e buscar equilíbrio. Ao passo de que os benefícios não são apenas pessoais, mas também para a comunidade e para o meio ambiente. Segundo o site do movimento o Slow Movement é uma corrente mundial e contemporânea que consiste em uma filosofia de vida que desafia a cultura da velocidade, do excesso e da quantidade sobre a qualidade. No mundo atual, em que as pessoas estão sempre com pressa e sobrecarregadas, o movimento, segundo o site Slow Movement (2016), defende que devemos tentar desacelerar, privilegiando a qualidade, o equilíbrio e o bem-estar nas diferentes áreas da vida.

O ideal do movimento é vivermos com desenvolvimento sustentável e solidário dinamizado pelas comunidades locais, e em articulação com o movimento de globalização que hoje vivemos (como complemento). Não é objetivo do Slow Movement ir contra o que tem sido conquistado até ao momento presente e existe um reconhecimento das importantes virtudes do mundo ocidental nas conquistas em batalhas pelos direitos humanos e na qualidade de vida, porém, o Movimento Slow surge como a expressão de um modelo alternativo perante as dificuldades do mundo atual e do atual modelo de desenvolvimento.

O movimento busca, através dos seus recursos, informações e serviços para facilitar a ação colaborativa entre as pessoas (SLOW MOVEMENT, 2016), juntando em uma rede de pessoas a responsabilidade ambiental e social. Suas ações estruturam-se em quatro conexões:

- $\quad$ Alimentação: Consumir alimentos orgânicos, prezar por uma alimentação saudável e favorecer pequenos produtores, incentivando o conceito slow;

- Território: Estar ligado a cultura e economia local, valorizar também a ecologia e o território;

- $\quad$ Pessoas: Valorização da comunicação e relacionamento com familiares, amigos e comunidade, reconhecendo vantagens do meio social; 
- Vida: Priorização e valorização do ritmo natural do corpo humano, prezando pelo bem-estar e afastando malefícios a saúde.

O Movimento Slow possui várias vertentes, como a Slow Travel (mais importante que a chegada é apreciar o caminho, ir sem pressa ou planos definidos), Slow pareting (dar às crianças uma infância com menos obrigações e mais valores que realmente fazem a diferença para crianças, como a interação com a família, ter amigos e contato com a natureza), Slow city (aumentar a qualidade de vida das pessoas, em que possam admirar e explorar o local onde vivem), Slow fashion (optam-se por produtos de vendedores locais ou provenientes de comércio justo, utilizam-se tecidos antigos reciclados e opta-se pela qualidade em detrimento da quantidade) e Slow schools (incluem aspectos pedagógicos, éticos e culturais, que visam formação integral do ser humano).

Nós podemos desenvolver um relacionamento sensato com a nossa experiência sensorial por meio da meditação consciente. Vivendo conscientemente somos incentivados a encontrar a calma. Quando praticamos a atenção plena na nossa vida cotidiana, estamos menos à mercê das nossas emoções destrutivas, e ficamos predispostos a maior inteligência emocional e equilíbrio. Portanto, ficamos mais dispostos a uma maior felicidade, pois viver conscientemente nos dá mais satisfação em nosso trabalho, em nossa família e em nossa vida em geral (SLOW MOVIMENT, 2016).

\section{Design e Sustentabilidade}

A sociedade está em um momento de transição de costumes e entendimentos sobre o mundo e suas limitações. Os designers caminham junto com essa mudança social tendo, agora, noção que as decisões de design "moldam os processos por trás dos produtos que utilizamos, os materiais e a energia necessária para produzi-los, o modo como operamos no dia-a-dia e o que acontece com eles quando perdem a utilidade" (THACKARA, 2008 p.24). Sendo assim, designers passaram a ter uma preocupação socioambiental muito mais elevada, buscando inserir o conceito de desenvolvimento sustentável em seus projetos.

A introdução do conceito de desenvolvimento sustentável como elemento de ordem na concepção de novos produtos trouxe aos projetistas a consciência de seu papel em grande cadeia de intervenções, diretas e indiretas, sobre o meio ambiente. (BARBOSA, 2009, p.94).

Manzini (2008) reforça a necessidade de diminuir o consumo de recursos ambientais e de regenerar o ambiente físico e social, lembrando que esse processo de mudança para a sustentabilidade deve acontecer como resultado de uma escolha positiva, e não como reação a eventos desastrosos ou imposições autoritárias. Em síntese, "deve basear-se em uma transformação capaz de ser entendida por aqueles que a vivem como uma melhoria nas condições de vida (seja individual ou coletiva)" (MANZINI, 2008, p.27). Para o autor a orientação de inovação rumo à sustentabilidade para designers deve recair na sua capacidade de orientar às próprias atividades, definindo objetivos que combinem suas próprias necessidades e exigências com os critérios da sustentabilidade que estão gradualmente vindo à tona. Sendo o mesmo também válido para empresas e cidadãos comuns em suas comunidades. Ou seja, novas (e sustentáveis) soluções devem ser concebidas e desenvolvidas (MONT, 2002). Para Thackara, o design consciente envolve uma determinação de: 
consideração os sistemas naturais, industriais e culturais que constituem o contexto das nossas ações como designers;

- $\quad$ Pensar em fluxos de materiais e energia em todos os sistemas que projetamos;

- $\quad$ Priorizar o ser humano e não tratá-lo como um mero fator "fator" em um contexto mais amplo;

- $\quad$ Entregar valor às pessoas e não entregar pessoas aos sistemas;

- $\quad$ Tratar o "conteúdo" como algo que se faz, não algo que se vende;

- Lidar com a diferença cultural, de local e de tempo como valores positivos, não como obstáculos;

- $\quad$ Concentrar-se em serviços, não em coisas, e evitar encher o mundo com dispositivos sem sentido" (THACKARA, 2008, p.38)

Se os designers não tinham noção de sua importância ambiental, econômica e social perante a produção e concepção de produtos, agora existe o conhecimento. Dessa forma a profissão pode ter contribuído para impactos ambientais, algumas vezes por indiferença e outras por desconhecimento, mas atualmente é sabido que um número enorme de designers trabalha arduamente para criação de produtos e serviços menos prejudiciais à biosfera. Partindo dessa ideia Thackara (2008) afirma que designers estão evoluindo de criadores de objetos para capacitadores de mudança.

\section{Mobiliário urbano}

Mobiliário urbano pode ser conceituado, segundo o Manual de Implantação de mobiliário urbano na cidade do Rio de Janeiro (1986), como "coleção de artefatos implantados no espaço público da cidade, de natureza utilitária ou de interesse urbanístico, paisagístico, simbólico ou cultural". Para a Prefeitura de Florianópolis (2012), mobiliário urbano é o conjunto de elementos que podem ocupar o espaço público, implantados, direta ou indiretamente, pela administração municipal.

Entretanto, esse tipo de conceituação não aprofunda a necessidade das cidades a respeito dos mobiliários urbanos. Para Montenegro (2005) é necessário entender as funções e atribuições desses objetos no espaço urbano. O autor afirma que mobiliários urbanos surgiram da necessidade das cidades em se adaptar as demandas dos habitantes das crescentes cidades do final do século XIX e início do século XX, como limpeza urbana, iluminação, segurança, entre outros.

Dentro desse contexto os mobiliários urbanos representam grande importância nas cidades, pois por meio deles, há a valorização dos espaços públicos de diferentes formas, sendo para lazer, segurança, transporte, conscientização ou prestação de serviços.

\subsection{Condições gerais}

Como condição geral dos mobiliários urbanos a NBR 9050 (2015) recomenda que o mobiliário proporcione segurança ao usuário, assegure dimensão adequada para uso, manipulação e manutenção do objeto, não possua cantos vivos perfurantes ou cortantes, esteja localizado fora da faixa livre para circulação dos pedestres, seja projetado de forma a não se construir objeto suspenso e estar localizado em rota acessível.

\subsection{Uso nos espaços}


A assimilação dos ambientes está relacionada com a maneira com que os habitantes da cidade os ocupam e com as atividades praticadas nestes locais. Logo, o mobiliário urbano, entendido como parte do espaço público influencia na escolha das pessoas por utilizarem um determinado local da cidade (FRANCIS, 1993). Para Ferrari (1984) afirma que os espaços urbanos formas uma cadeia de fluxos, em que tráfego, mobiliários urbanos e áreas urbanas estão interligados e influenciam na vida socioeconômica da comunidade. Pode-se, então, concluir que um mobiliário urbano, além de cumprir as necessidades para as quais foi concebido, afeta a usabilidade dos espaços.

Essa influência vai além apenas da escolha de ir até o local, mas afeta o tempo de permanência e a frequência de deslocamento até o determinado local. Isso é determinado porque o mobiliário influencia a qualidade do espaço em que está inserido, sendo assim:

\begin{abstract}
Projetos específicos de mobiliário urbano que consideram os parâmetros condicionantes e seu contexto, criam um diferencial, valorizando os espaços livres públicos, definindo, então, padrões de qualidade. Nesse aspecto, os elementos urbanos desempenham um papel singular na medida em que podem ajudar o cidadão a utilizar os espaços urbanos de maneira mais efetiva seja através das suas funções explícitas associadas à contemplação, ao relaxamento e ao lazer, ou nas funções implícitas e abstratas relacionadas com a identificação e compreensão do espírito do local pelo usuário através dos simbolismos representados naqueles elementos. (MONTENEGRO, 2005, p. 48).
\end{abstract}

Nesse contexto deve-se então avaliar o local a inserir o mobiliário, bem como aspectos sociais, culturais, ambientais e econômicos. Com essa observação mais detalhada da cidade ou comunidade tem se mais sólida a certeza de que os habitantes vão se sentir um pertencimento ao bem público e serão influenciados pelas dinâmicas proporcionadas pelo mobiliário urbano.

\title{
5.3 Produto modular
}

Modularidade é o termo utilizado para definir unidades comuns para variação de um produto. Segundo Huang e Kusiak (1998) "seu foco é a identificação de unidades independentes, padronizadas ou intercambiáveis para satisfazer uma variedade de necessidades". As partes (módulos) podem funcionar individualmente, mas funcionam como um conjunto integrado. Produtos modulares são economicamente e tecnicamente mais favoráveis, além de que produtos com módulos podem facilitar o conserto, manutenção, montagem, desmontagem, reuso e reciclagem (PAZMINO, 2003).

Um produto modular é um sistema que cumpre sua função por meio da combinação de diferentes módulos. Esses módulos são componentes do sistema e interagem com outros módulos criando assim variações de um mesmo produto. O que facilita a produção do produto, assim como sua combinação com os diferentes módulos é que os componentes são padronizados (AMARO, 2016).

\section{Desenvolvimento}

\subsection{Sentir}

$\mathrm{Na}$ fase inicial do projeto foram coletados dados para diretrizes iniciais de projeto. Para que esse levantamento fosse realizado foram criadas perguntas descritivas (afim de analisar renda, gênero e idade), comportamentais (análise de comportamento social e pessoal) e preferenciais (com intuito de saber opiniões das pessoas). Foram aplicados dois questionários, o primeiro para toda a população de Florianópolis e o segundo apenas para a 
comunidade universitária do Centro de Comunicação e Expressão (CCE). O primeiro questionário foi disponibilizado de forma online para pessoas de ambos os sexos e esteve disponível para o público entre os dias 8 e 15 de outubro de 2016 e contou com 182 participantes. O segundo também foi disponibilizado pela internet, entre os dias 26 e 31 de março de 2017 e contou com 59 participantes.

Foi optado pela criação de dois questionários para primeiramente ter noção de comportamentos na cidade como um todo e depois da comunidade específica estudada. A intenção é entender se o comportamento da comunidade se difere muito do comportamento da cidade no geral e estar ciente do comportamento geral da população do município, levando em consideração que a universidade é um ambiente público, podendo ser frequentada por qualquer pessoa.

O primeiro questionário foi composto pelo total de 20 perguntas, em que três questões foram discursivas, duas delimitadas para respostas curtas e uma ao final optativa para deixar algum comentário sobre o assunto ou sobre o questionário. As outras 17 perguntas caracterizavam-se por ser de múltipla escolha, afim de uma padronização para tabulação dos dados.

Para uma melhor visualização dos dados mais relevantes retirados do primeiro questionário, foi feita uma síntese das respostas (figura 1).

Figura 1 - Dados mais relevantes do primeiro questionário

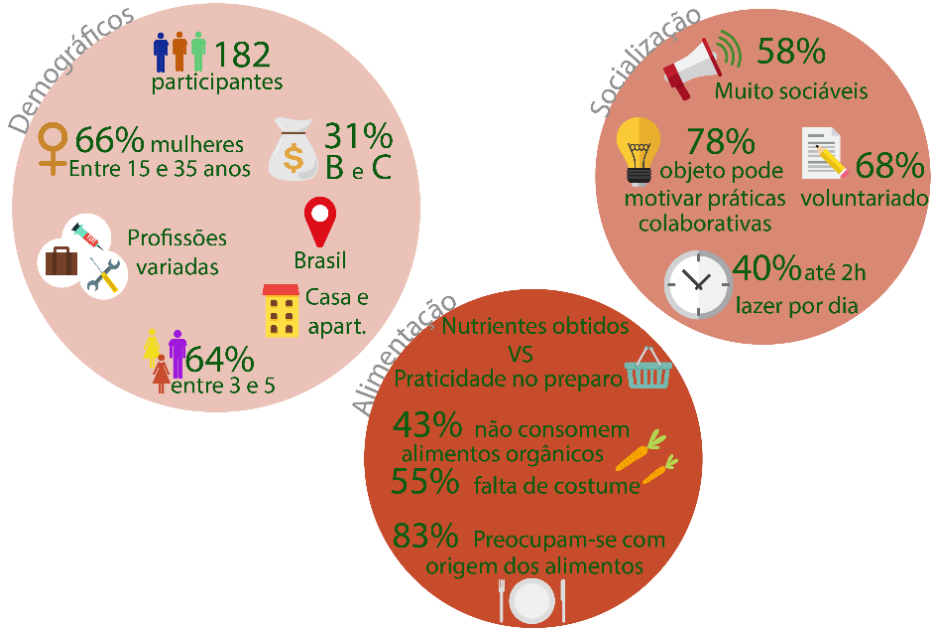

Fonte: Autora (2017)

O segundo questionário foi composto pelo total de 15 perguntas, sendo 13 de múltipla escolha, afim de uma padronização de dados, uma descritiva e uma ao final optativa para deixar algum comentário sobre o questionário.

Para uma melhor visualização dos dados mais relevantes retirados do segundo questionário foi feita uma síntese das respostas (figura 2).

Figura 2 - Dados mais relevantes do segundo questionário 


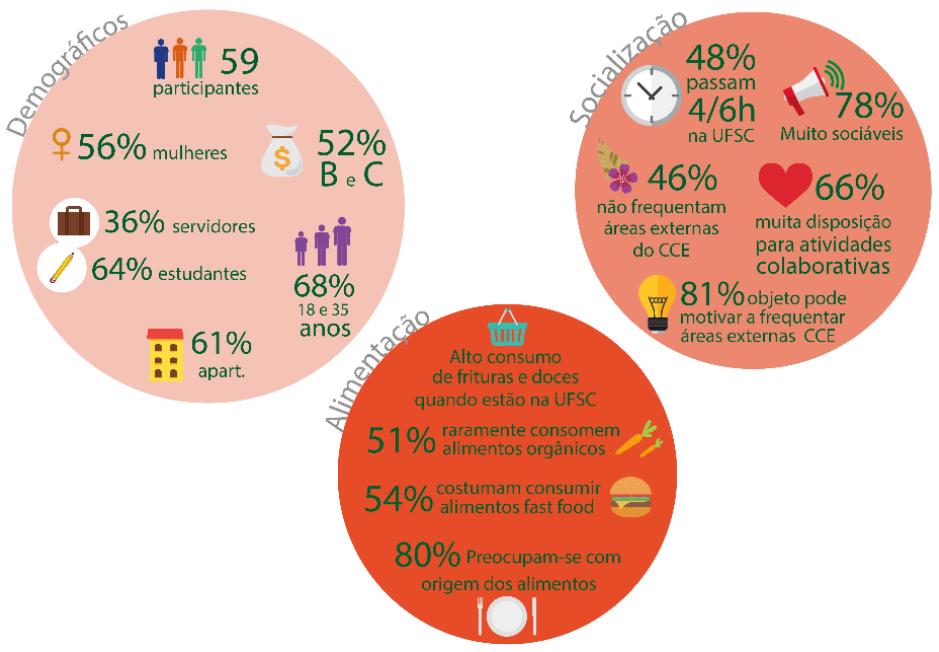

Fonte: Autora (2017)

Em seguida foi realizada uma observação direta do comportamento dos possíveis usuários. A observação é uma técnica importante para observar como as pessoas agem dentro de um contexto real, sem interferir em suas atividades.

A observação foi realizada nas áreas abertas em volta do CCE e teve duração de cinco dias. O principal objetivo observação foi entender como as pessoas se comportam nas áreas do CCE, quem a frequenta, o que as pessoas consomem e o que fazem quando estão nesses locais. Imagens da observação, assim como análises da autora referente as observações, encontram-se sintetizadas na figura 3.

Figura 3 - Observação realizada no CCE e análises da autora

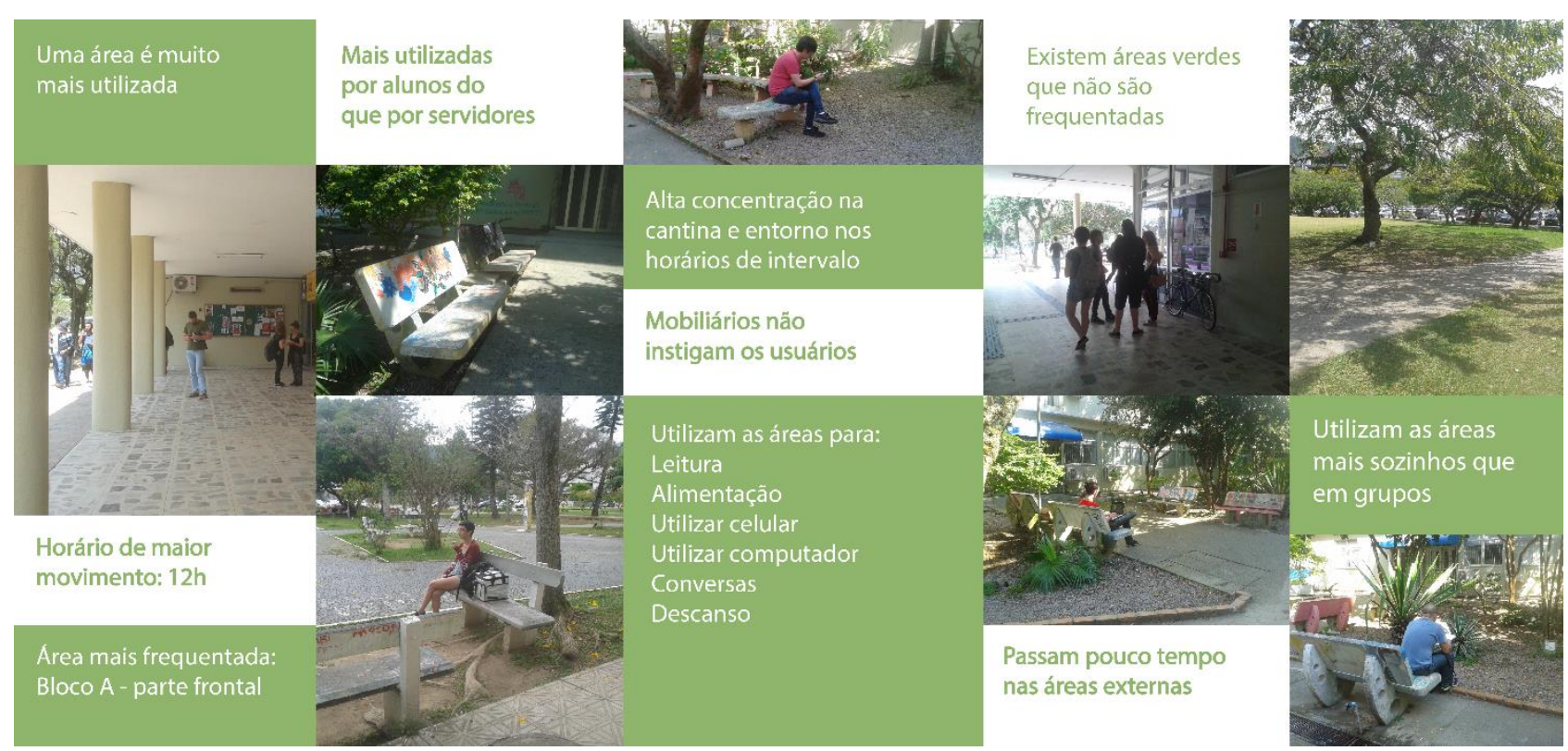

Fonte: Autora (2017)

Após a observação foi aplicada a ferramenta de Nuvem de palavras. A Nuvem de palavras é 
um método heurístico de análise, no entanto aponta caminhos para o quê se observar em meio a um grande número de respostas. As palavras com maior destaque na nuvem são maiores pois foram as palavras mais faladas pelos entrevistados.

Nas áreas externas do CCE foram abordadas 50 pessoas e, para elas foi perguntado "O que você acredita que falta nos mobiliários urbanos do CCE?". Foi solicitado que elas citassem preferencialmente adjetivos e frases curtas. A nuvem de palavras das respostas encontra-se na Figura 4.

Figura 4 - Nuvem de palavras

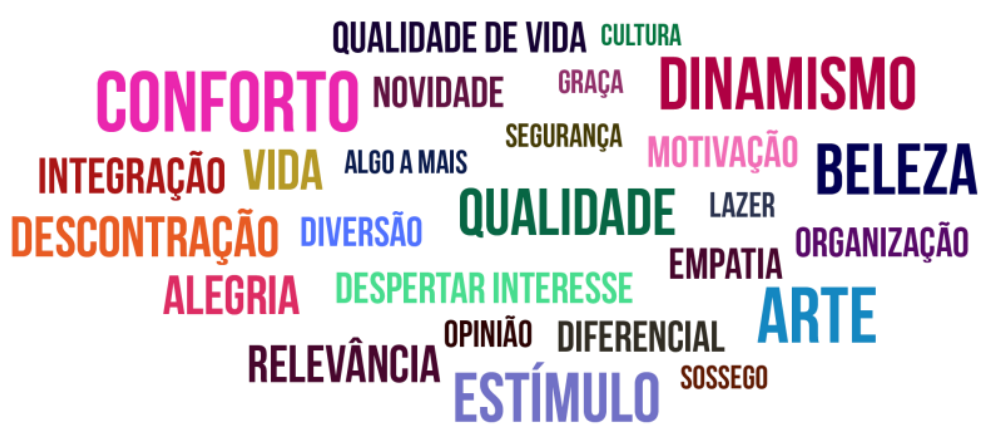

Fonte: Autora (2017)

\subsection{Agir}

Essa etapa funciona como sintetizadora de todas as informações recolhidas até o momento. A partir de todos os dados obtidos na primeira etapa do processo, assim como as pesquisas teóricas iniciais, inicia-se um processo de interpretação e síntese das pesquisas.

Foram criados requisitos de projeto. Essa lista foi baseada nas análises e pesquisas realizadas durante o todo o processo. Para melhor organização dos requisitos, houve uma divisão em três grupos: requisitos de produto, usuário e contexto de uso. Essa divisão dos requisitos foi retirada da metodologia Guia de Orientação para Desenvolvimento de Projetos (GODP), processo projetual desenvolvido por Merino (2016).

Os requisitos de usuário consistem nas necessidades do usuário observadas durante o processo de pesquisa:

1. Fácil manuseio, que possibilite uma abordagem prática do usuário.

2. Sem cantos ou pontas vivas ou cortantes, visando segurança do usuário.

3. Objeto modular, trazendo a possibilidade de interação e dinamismo, que o usuário possa manusear conforme lhe for mais conveniente.

4. Integrar elementos vivos ao projeto, como temperos e pequenos vegetais, como fins terapêuticos (trazendo tranquilidade ao usuário) e aguçando os sentidos tato (contato com a planta), paladar (possibilidade de colher e comer), olfato (exalando o perfume das plantas) e visão (explorando cores e formatos dos alimentos), tudo promovendo o incentivo à alimentação saudável e ao movimento Slow food.

Requisitos de produto consistem nas exigências referentes à forma, processos fabris, materiais e texturas do objeto: 
5. Utilizar as cores próprias dos materiais utilizados para confecção do produto.

6. Processo fabril de complexidade possível localmente, incentivando o desenvolvimento econômico local.

7. Deve integrar as funções de socialização, práticas colaborativas e incentivo à alimentação limpa (sem elementos sintéticos e sem produtos tóxicos da indústria química) e boa (valorizar alimentos da estação, valorizar alimentos bons para saúde, trazer sensação prazerosa relacionada à alimentação saudável).

8. Produto dinâmico, promovendo a criatividade dos usuários.

9. Utilizar algum elemento de reciclagem, transmitindo preocupação ambiental e incentivando o usuário a replicar a ideia.

Requisitos de contexto de uso referem-se à necessidades entendidas a partir do tipo de ambiente em que o produto estará inserido e de como ele será usado:

10. O produto deve ser resistente, pois será criado para uso outdoor, então deve resistir a intempéries e condições climáticas desfavoráveis.

11. Design clean (limpo), que não "polua" com muitas informações o lugar em que está inserido.

\subsection{Realizar}

Essa fase marca o início da implementação de soluções para o projeto. Nessa etapa são realizados os modelos ou protótipos do produto final, assim como definição de materiais, custos e processos.

O mobiliário consiste em três principais peças modulares, peças que se encaixam para formar bancos e uma peça para horta vertical. O banco é constituído por duas partes para que a parte de cima possa ser encaixada em outro banco, gerando nova altura de banco, que pode ser usada tanto para assento ou encosto quanto para apoiar objetos de uso pessoal, como computadores, mochilas ou embalagens alimentícias. $\mathrm{O}$ assento do banco também é removível, para que em dias de chuva possa alterar o lado do assento sem ter que esperar secar um lado e também para que a comunidade possa armazenar dentro do banco garrafas pet para uso na horta vertical ou ainda utilizar esse espaço para plantações. A horta vertical é encaixável nos assentos e pode ser transferida de um assento para o outro. Todas as peças mencionadas encontram-se na figura 5.

Figura 5 - Peças do mobiliário 


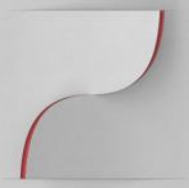

\section{Artigo Completo}

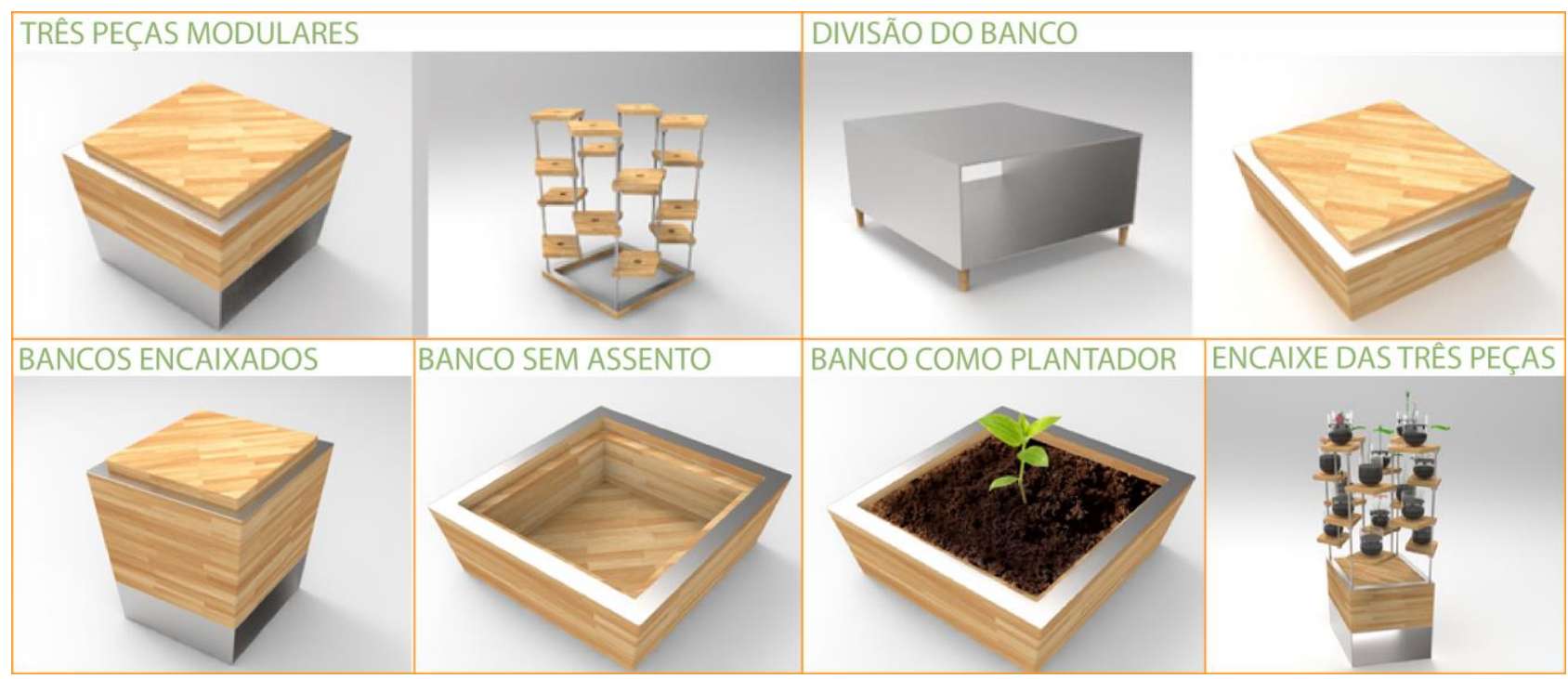

Fonte: Autora (2017)

$\mathrm{Na}$ horta vertical encontram-se encaixes para garrafas pet de $250 \mathrm{ml}$ até 2 litros (Figura 6), a intenção com a escolha desse material é que os usuários deem um novo uso para as garrafas pet que utilizarem e as possam trazer e levar para casa, criando um ciclo de plantações na horta vertical. Esse contato com as plantas possibilita ao usuário uma maior aproximação com a alimentação saudável, com o movimento slow food, com as práticas colaborativas e com a cultura slow de forma geral. Espera-se que o usuário faça um rodízio de plantas no local, em que leva para sua casa as que tem interesse e também traga outras para que as outras pessoas da comunidade desfrutem do produto. As garrafas pet foram escolhidas para utilização no projeto porque o plástico ainda é o material menos reciclado no Brasil (Landim, 2015), ainda segundo o autor $40 \%$ das garrafas pet não são recicladas no país.

Figura 6-Garrafas pet na horta vertical

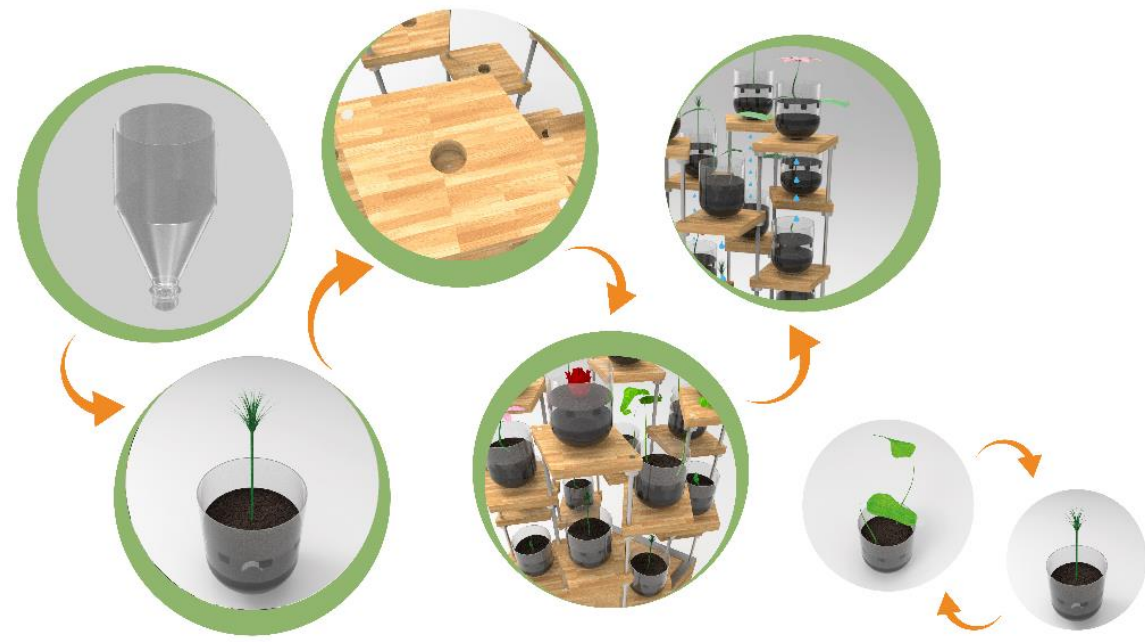

Fonte: Autora (2017)

O modelo final do produto foi desenhado e modelado no programa SolidWorks. A 
renderização foi realizada no programa Keyshot 7. Em seguida foram realizadas ambientações do produto no programa Photoshop CC em contexto real e semelhante (figura 7).

Figura 7 - Ambientação em contexto real

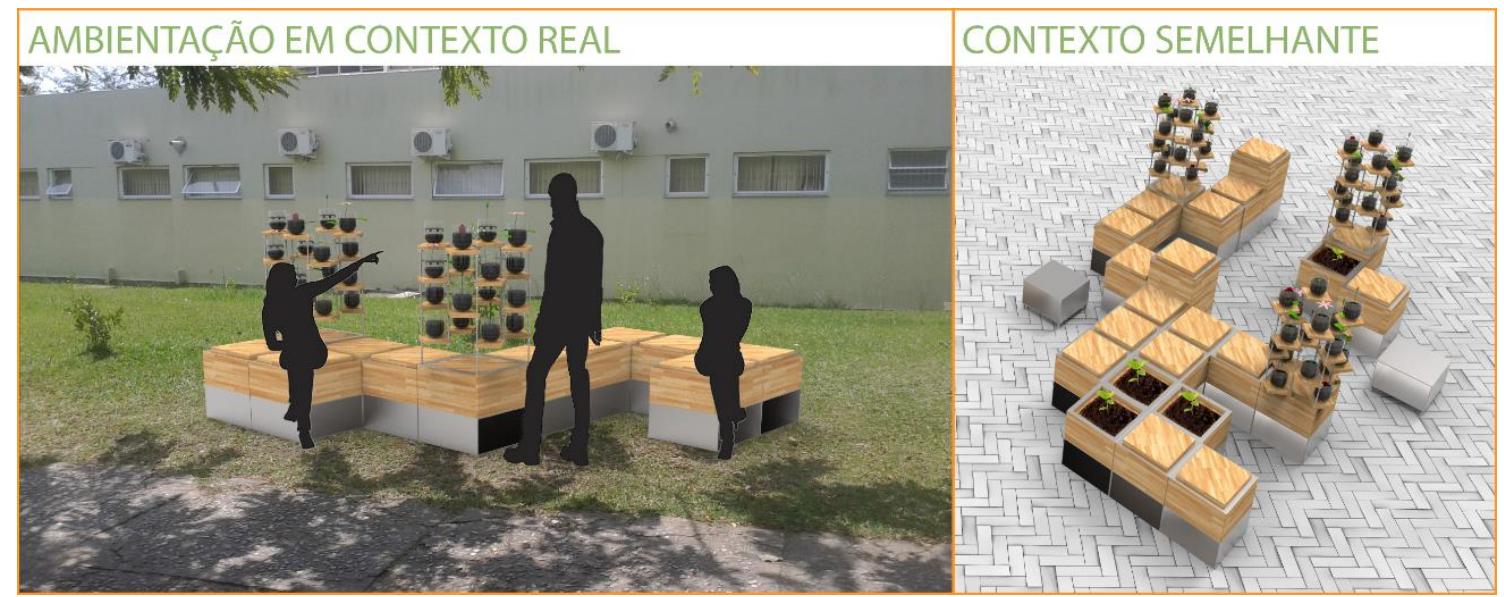

Fonte: Autora (2017)

Para escolha dos materiais do projeto foram levados em consideração aspectos referentes a durabilidade, sustentabilidade, os requisitos de projeto, adequação ao contexto de uso e estética. Foram escolhidos então a madeira e o aço galvanizado.

A madeira causa baixo impacto no ambiente. É um material biodegradável, não poluente e pode ser reciclada ou usada como biocombustível no fim da vida útil (THOMPSON, 2015). A madeira Teca é nativa da Índia, Tailândia, Laos e Mianmar, entretanto é plantada no Brasil desde 1990 (WALOTEK, 2017). Foi escolhida para o assento dos bancos e também para o encaixe nos bancos pois é uma madeira de alta qualidade, alta durabilidade, muita estabilidade, boa densidade, possui alta resistência à intempéries, chuva e sol, suportando seus efeitos agressivos sem deformar, rachar ou dividir, possui alta resistência também a insetos e fungos. Possui resinas naturais que repelem cupins, facilidade na aplicação, na colagem e polimento, manutenção simples e é muito plantada no Brasil (PEREIRA, 2013).

$\mathrm{O}$ aço consiste em uma liga metálica constituída basicamente de ferro e carbono (de $0,002 \% \mathrm{~m} / \mathrm{m}$ até $2,00 \% \mathrm{~m} / \mathrm{m}$, aproximadamente), obtida pelo refino de ferro-gusa em equipamentos apropriados, sendo um material muito versátil e possuindo propriedades bastante específicas. Apesar do aço ser um material que consome muita energia para obtenção, além de carbono e resíduos é um material em que muitas fábricas já usam ingredientes reciclados para reduzir o consumo de energia e emissões. Segundo Thompson (2015) é um material extremamente durável e tem uma reciclabilidade muita alta, sendo facilmente separado de fluxos de resíduo porque é magnético, podendo ser remodelados muitas vezes sem perder qualidade e desempenho. $\mathrm{O}$ aço foi escolhido para material de base do produto pois é muito resistente à corrosão, boa conformabilidade, muita resistência e ductabilidade (DIAS, 1998).

O modelo final foi realizado em escala 1:1, e para o desenvolvimento foram utilizados os seguintes materiais: chapa de aço galvanizado, tubos de alumínio, parafusos com porcas, mdf, madeira OBS e plástico Abs. O modelo final encontra-se na figura 8. 
Figura 8 - Ambientação em contexto real

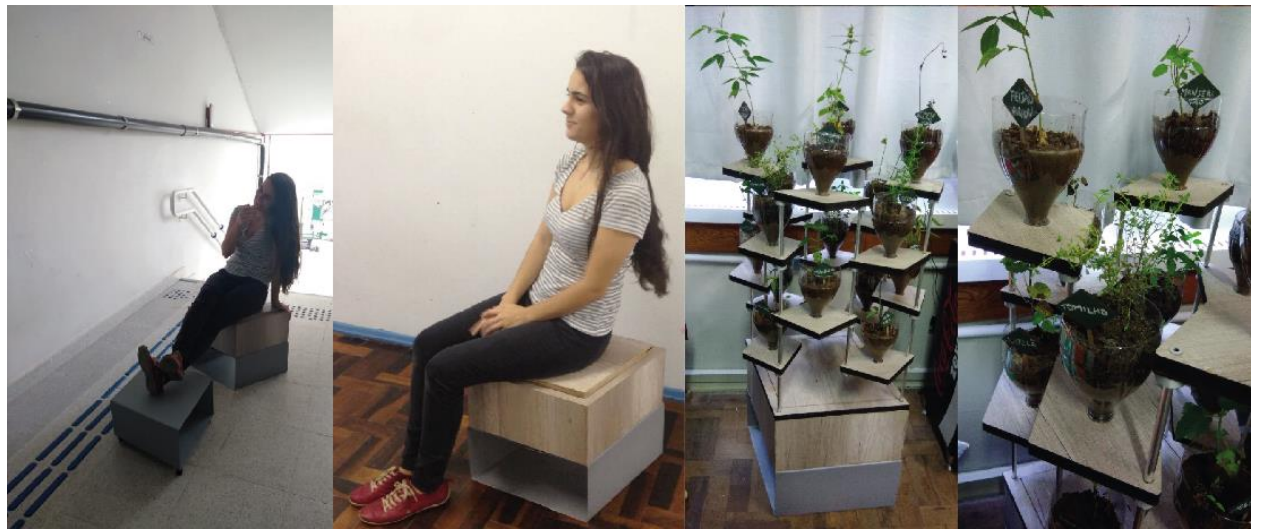

Fonte: Autora (2017)

\section{Considerações finais}

O movimento slow é uma cultura em ascensão, que preza pela valorização das relações pessoais, do bem-estar, do equilíbrio no uso do tempo e preza por qualidade sobre a quantidade. A tendência de que cada vez mais pessoas se sintam atraídas por esse estilo de vida é presente não só em Florianópolis, mas no Brasil, saindo do contexto de vida turbulento vivido atualmente para um equilíbrio de vida, em que a valorização pela saúde mental e física é real e necessário. Esse novo contexto exige que o design crie serviços e produtos que facilitem e incentivem essas preocupações, contribuindo com projetos que proporcionem bem-estar às pessoas.

Dessa forma o projeto foi baseado nesse contexto, e buscou atender as necessidades e desejos dos usuários com um método que prioriza o usuário e o coloca como prioridade, utilizando para isso o Guia Projetual NASDesign. O projeto buscou propor como o design pode contribuir, pensando no usuário, para motivar as práticas da cultura slow. O produto propõe a fomentação dessa prática dentro das diretrizes da sustentabilidade, dando devida atenção as necessidades sociais, ambientais e econômicas, que também é uma preocupação da cultura slow.

Como produto final obteve-se um mobiliário urbano diferenciado, que atende as exigências e objetivos de projeto, atende os requisitos de sustentabilidade e que motiva as práticas colaborativas, a integração e dinâmica social, a alimentação saudável, o contato com as diferentes fases do alimento e a atenção ao bem-estar, que são princípios básicos da cultura slow.

O projeto previa atender os princípios da cultura slow e os fundamentos da sustentabilidade, tendo o foco no usuário. Esses três principais pilares do projeto (cultura slow, usuário e sustentabilidade) foram amplamente atendidos, em que o projeto atinge as três esferas da sustentabilidade (social, ambiental e econômica) e as quatro esferas da cultura slow (vida, pessoas, alimentação e território).

Definiu-se um público para obter diretrizes de projeto, entretanto apesar de o projeto ter um público-alvo específico a solução proposta atende a públicos mais amplos, sendo viável a implementação do projeto para outros públicos e comunidades.

Entende-se que a importância mercadológica do projeto está em aumentar a visibilidade da cultura slow nos produtos. A importância social se dá pelo encorajamento de mudança do comportamento do usuário, incentivando as tendências da cultura slow e do movimento Slow 
food, trazendo a preocupação com a alimentação saudável e o contato com o mesmo, também incentivando gestores de comunidades a criarem mobiliários urbanos amigáveis, que atendam as expectativas e necessidades dos usuários. Pretende-se também com esse projeto motivar outros designers a criarem produtos e serviços que estejam no contexto da sustentabilidade e motivem a cultura slow.

É importante ressaltar que o produto foi projetado pensando em uma mudança social em ascensão, que é uma sociedade ambientalmente e socialmente correta, que está disposta a compartilhar espaços e produtos, assim como também contribuir para sua manutenção. Entretanto em uma possível aplicação real do produto existe a possibilidade de acontecerem furtos. Nesse caso o produto é facilmente adaptado para uma fixação no solo por meio de uma placa de inox que os interligaria, assim como todos os módulos também podem ser facilmente fixados entre si. Porém essa fixação acarreta em uma perda da dinâmica de mobilidade que os módulos do mobiliário propõem ao usuário.

\section{Referências}

AROS, Kammiri Corinaldesi. Elicitação do processo projetual do Núcleo de Abordagem Sistêmica do Design da Universidade Federal de Santa Catarina. Orientador: Luiz Fernando Gonçalves de Figueiredo - Florianópolis, SC, 2016.

ASSOCIAÇÃO BRASILEIRA DE NORMAS TÉCNICAS. NBR 9050. Acessibilidade a edificações, mobiliário, espaços e equipamentos urbanos. Rio de Janeiro: ABNT, 2015.

BARBOSA FILHO, Antonio Nunes. Projeto e Desenvolvimento de Produtos - São Paulo : Editora Atlas S.A. - 2009.

BAIN E COMPANY. Macrotendências do Comportamento do Consumidor. Disponível em: $<$ http://www.bain.com/offices/saopaulo/pt/press/the-five-behavioral-trends-that-will-influencethe-brazilian-consumption-in-the-coming-years-according-to-bain-and-company.aspx>. Acesso em: 21 set. 2016

BRUNEL, Felipe Kanarek; "O DESIGN ESTRATÉGICO EM NÍVEL METAPROJETUAL COMO SUPORTE PARA A INOVAÇÃO SOCIAL: o caso SLOW FOOD", p. 202-210 . In: Anais do 5o Simpósio Brasileiro de Design Sustentável [=Blucher Design Proceedings, v.2, n.5]. São Paulo: Blucher, 2016. ISSN 2318-6968, DOI 10.5151/despro-sbds15-2st701b

CAPELLO, Giuliana. Slow Life: vida mais calma, lenta e confortável. Planeta Sustentável: 16 set 2008. Disponível em: <http://planetasustentavel.abril.com.br/blog/gaiatos-e-gaianos/109647/>. Acesso em: 4 out. 2016.

FUNDAÇÃO TELEFÔNICA VIVO. Visões de futuro +15. Disponível em:< http://fundacaotelefonica.org.br/visoesdefuturo?_ga=2.185379817.1782734541.15077311321054231122.1507074250>. Acesso: 30 set. 2016.

HUANG, Chun-Che; KUSIAK, Andrew. IEEE Transactions on systems, man and cybernetics - Part A: Systems and Humans. - Modularity in Design of Products and Systems. Vol. 28, N. 1. (1998).

LANDIM, A. P. M. Sustentabilidade quanto às embalagens de alimentos no Brasil, 2015. Disponível em:< http://www.scielo.br/pdf/po/2016nahead/0104-1428-po-0101-14281897.pdf> Acesso em: 30 set. 2017. 
MANZINI, Ezio. Design para a inovação social e sustentabilidade: Comunidades criativas, organizações colaborativas e novas redes projetuais. Rio de Janeiro: E-papers, 2008. 104 p. (Caderno do Grupo de Altos Estudos do PEP/UFRJ; v.1).

MANZINI, Ezio. Making Things Happen: Social Innovation and Design. Design Issues: v.30 n.1, 2014.

MANZINI, Ezio. Design, when everbody designs: an introduction to design for social innovattion. Cambridge: MIT Press Book, 2015. 241p.

MERINO, Giselle Schmidt Alves Díaz. GODP - Guia de Orientação para Desenvolvimento de Projetos: Uma metodologia de Design Centrado no Usuário. Florianópolis: NGD/ UFSC, 2016. Disponível em: (www.ngd.ufsc.brı. Acesso em: 12 mar. 2017

PAZMINO, Ana Verônica. Projeto de Produtos Modulares: Material de aula de tópicos avançados. Capítulo 5. UDESC, Joinville, 2003.

PEREIRA, Andréa Franco. Madeiras brasileiras: guia de combinação e substituição. São Paulo: Blucher, 2013.

Slow Food Brasil, 2013. Disponível em: <http://www.slowfoodbrasil.com/>. Acesso em: 4 out. 2016.

Slow Moviment, 2016. Disponível em <http://www.slowmovement.com/slow_living.php> Acesso em: 4 de out. 2016

Slow Moviment Portugal, 2014. Disponível em: <http://www.slowmovementportugal.com/> Acesso em: 4 de out. 2016.

THACKARA, John. Plano B: o design e as alternativas viáveis em um mundo complexo - tradução Cristina Yamagami - São Paulo : Saraiva : Versar, 2008. 299 p.

WALOTEK, Przemyslaw Jan. Teca - Tectona Grandis L.f: a madeira mais valiosa do planeta. 2017. Disponível em: <https://app.magtab.com/reader/revista-crea-sc/17902\#page/15>. Acesso em: 20 set. 2017 